IZA DP No. 7078

Recent Developments in the Economics of Happiness:

A Selective Overview

Alois Stutzer

Bruno S. Frey

December 2012 


\title{
Recent Developments in the Economics of Happiness: A Selective Overview
}

\author{
Alois Stutzer \\ University of Basel, \\ CREMA and IZA \\ Bruno S. Frey \\ University of Warwick \\ and CREMA

\section{Discussion Paper No. 7078 \\ December 2012} \\ IZA \\ P.O. Box 7240 \\ 53072 Bonn \\ Germany \\ Phone: +49-228-3894-0 \\ Fax: +49-228-3894-180 \\ E-mail: iza@iza.org
}

\begin{abstract}
Any opinions expressed here are those of the author(s) and not those of IZA. Research published in this series may include views on policy, but the institute itself takes no institutional policy positions. The IZA research network is committed to the IZA Guiding Principles of Research Integrity.

The Institute for the Study of Labor (IZA) in Bonn is a local and virtual international research center and a place of communication between science, politics and business. IZA is an independent nonprofit organization supported by Deutsche Post Foundation. The center is associated with the University of Bonn and offers a stimulating research environment through its international network, workshops and conferences, data service, project support, research visits and doctoral program. IZA engages in (i) original and internationally competitive research in all fields of labor economics, (ii) development of policy concepts, and (iii) dissemination of research results and concepts to the interested public.
\end{abstract}

IZA Discussion Papers often represent preliminary work and are circulated to encourage discussion. Citation of such a paper should account for its provisional character. A revised version may be available directly from the author. 


\section{ABSTRACT \\ Recent Developments in the Economics of Happiness: A Selective Overview*}

What makes people happy in life? This is a crucial question that has the potential to shake up economics. In recent years, the dissatisfaction with the understanding of welfare in economics together with the new opportunities to empirically study people's subjective wellbeing have spurred impressive and stimulating new research in the often called dismal science. The economics of happiness has emerged as one of the most thriving areas in current economic research. This introductory chapter refers to important contributions to the economics of happiness that characterize the recent developments in the area. First, we refer to reviews of the literature, the measurement and the relationship of happiness research to welfare economics. Second, we emphasize four factors from the large literature on the determinants of happiness in economics, i.e. income, employment, social capital and health. In fact, the main body of research in this new area is on the preconditions or covariates of high individual well-being. Third, important studies applying the so-called Life Satisfaction Approach as an alternative valuation approach are discussed. Fourth, we point to contributions that elaborate on the understanding of utility in terms of people's adaptation to circumstances and their difficulties in predicting future utility. Fifth, we provide references to the controversial question regarding the policy consequences of this new development.

JEL Classification: $\quad$ I31

Keywords: happiness, individual welfare, Life Satisfaction Approach, subjective well-being

Corresponding author:

Alois Stutzer

Faculty of Business and Economics

University of Basel

Peter Merian-Weg 6

4002 Basel

Switzerland

E-mail: alois.stutzer@unibas.ch

" Introductory chapter prepared for the volume "Recent Developments in the Economics of Happiness" in the Elgar collection of Critical Writings in Economics. 


\section{Introduction}

What makes people happy in life? This is a crucial question that has the potential to shake up economics. In recent years, the dissatisfaction with the understanding of welfare in economics together with the new opportunities to empirically study people's subjective well-being have spurred impressive and stimulating new research in the often called dismal science. The economics of happiness has emerged as one of the most thriving areas in current economic research.

This volume presents a collection of important contributions to the economics of happiness that characterize the recent developments in the area. The papers build on an early literature that has been documented in Richard Easterlin's collection "Happiness in Economics" (2002) in the same series.

In this introductory chapter, we put these papers in the context of the literature at large. We are aware that this is a difficult venture. The number of published articles referenced in EconLit in any given year that mention happiness, life satisfaction or subjective well-being in the title or abstract has increased from 3 in 1986-90 to 146 in 2011. Figure 1 depicts the development in the number of referenced publications since the early nineties. It clearly shows a take-off after 2000. Many more papers are in the pipeline and available as working papers. Google Scholar lists more than 20’000 papers for the year 2011 that include the terms happiness and economics somewhere in the text.

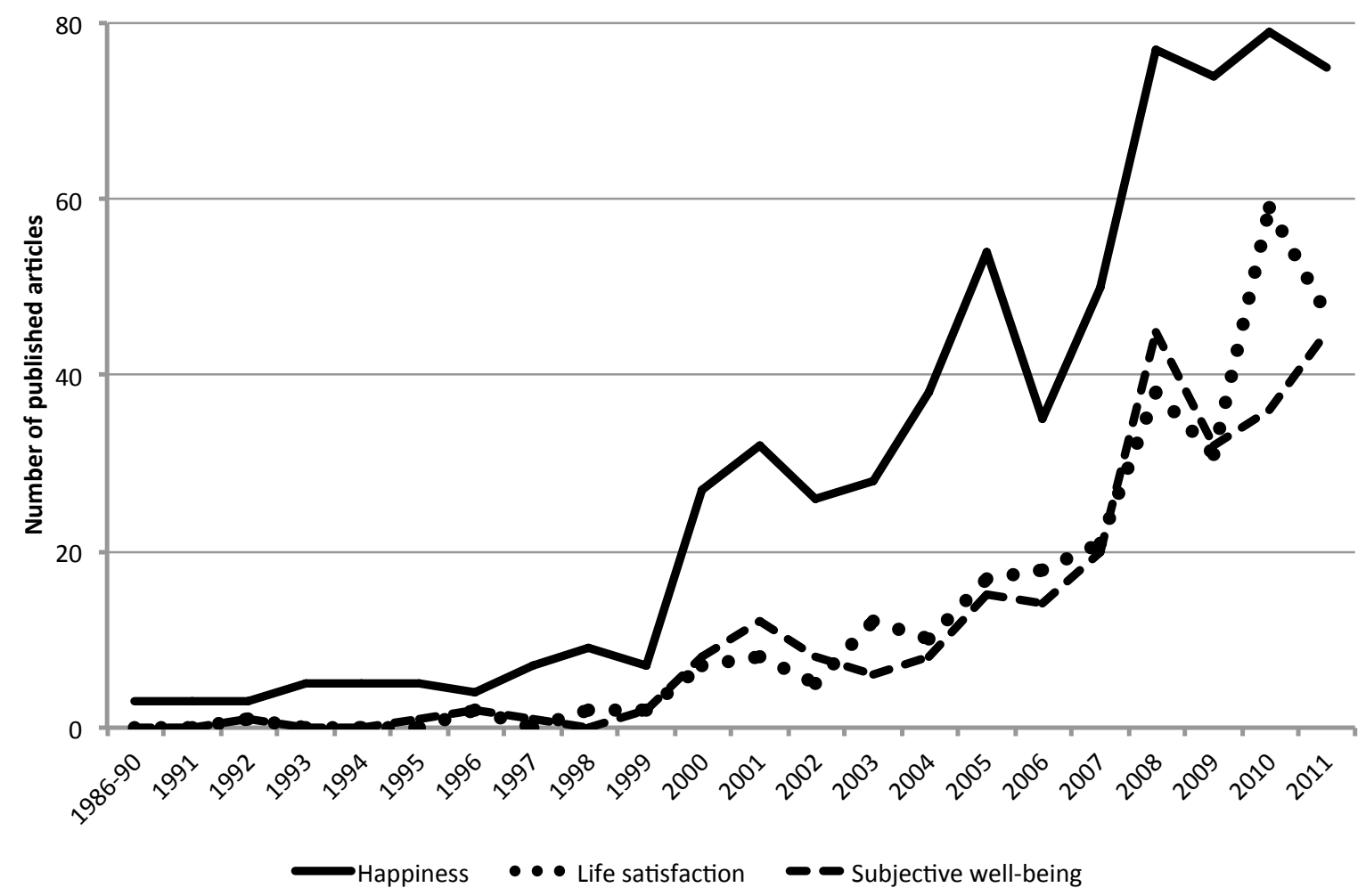

Figure 1. Number of published articles on the economics of happiness referenced in EconLit between 1986 and 2011

Source: Own compilation based on EconLit. 
We organize the selection of articles as well as this chapter along five broad issues. First, we refer to reviews of the literature, the measurement and the relationship of happiness research to welfare economics. Second, we emphasize four factors from the large literature on the determinants of happiness in economics, i.e. income, employment, social capital and health. In fact, the main body of research in this new area is on the preconditions or covariates of high individual well-being. Third, important studies applying the so-called Life Satisfaction Approach as an alternative valuation approach are discussed. Fourth, we point to contributions that elaborate on the understanding of utility in terms of people's adaptation to circumstances and their difficulties in predicting future utility. Fifth, we provide references to the controversial question regarding the policy consequences of this new development.

\section{Reception of a New Approach in Economics}

The economics of happiness as an area in economics developed so far as a strongly empirical endeavor. It is spurred by the direct measurement of individuals' well-being. Thereby, economists built on instruments tested in psychology and included in many surveys by pollsters. While the various self-reported measures are the basis for the area's academic success, they are also still subject to many controversial discussions about the merits of the new approach in economics. Not all criticism is equally productive. Fundamental rejections of the new research tend to neglect a comparative perspective with past research and disregard the potential of happiness research to provide complementary insights. However, the skepticism has also motivated many productive analyses on the validity of the empirical measures (e.g. Krueger and Schkade 2008, Oswald and Wu 2010), has led to the development of new statistical tools to analyze survey data ${ }^{1}$, has given rise to new measures of subjective well-being, and has invigorated the debate about welfare in economics.

We present the selected papers as representative for a specific theme or question in the whole research enterprise, and we supplement them with additional references. We do not claim that our collection is comprehensive. However, the selection and the references in this introduction should facilitate access to the recent developments in the economics of happiness.

\section{a) Measuring happiness}

Happiness or subjective well-being how the various cognitive life evaluations and emotional reports are often called, can be measured by a number of instruments. Single- and multi-item survey questions on satisfaction with one's life capture the more evaluative aspects of individuals' well-being. The more emotional aspects are captured by questions on moment-tomoment affect. Two main approaches exist for the experienced well-being of affect. Psychologists have been applying the Experience Sampling Method for years. It collects

\footnotetext{
${ }^{1}$ Probably most relevant is the new interest in fixed effect estimators for panel data with ordinal dependent variables (e.g. Baetschmann et al. 2011). For practical applications, comparisons of the OLS estimator - treating the ordinal survey indicators as cardinal measures - with traditional estimators for ordinal data were helpful in simplifying many analyses (Ferrer-i-Carbonell and Frijters 2004).
} 
information on individuals' actual experiences in real time in their natural environments (see, e.g., Stone et al. 1999). Recently, a related new approach has been developed in a collaboration between psychologists and economists, the Day Reconstruction Method (DRM). People are asked to reflect on how they felt during all the life episodes they went through the previous day (Kahneman et al. 2004). Compared to the life satisfaction evaluation, the goal of the DRM is to get descriptions of emotional states and measures of well-being that are less formed by processes of retrospection. Furthermore, in combination with the time use information, the DRM aims to establish a cardinal indicator of well-being, by considering the time spent in a predominantly negative affective state. The recent developments in the measurement of subjective well-being are discussed in Kahneman and Krueger (2006) and Helliwell and Barrington-Leigh (2010). Many further arguments are brought up in a conference volume on the DRM as a concept for national accounts of time use and well-being (Krueger 2009).

\section{b) Welfare in economics}

The various measures mentioned capture different aspects of individual well-being and thus different concepts of individual welfare. For a measure of reported subjective well-being to serve as a proxy for individual welfare, an important assumption is necessary: The standards underlying people's judgments are those which an individual would like to pursue in realizing his or her ideal of the good life. People's judgments about their lives can then serve as a proxy for their individual welfare. People are assumed to pursue individual welfare based on some stable evaluation standards. Moreover, the extent to which individual welfare is identified depends on whether the evaluation metric fits people's judgments about their lives.

The normative basis of the happiness approach thus goes beyond assuming the pursuit of happiness, and also involves choosing the concrete evaluation metric to elicit people's judgments. An excellent account of the ambiguities of welfare in the context of economics and hedonic psychology is provided in Kelman (2005).

The ambiguities can be expressed in familiar terms. Some people might favor a distant look reflecting on their life after the fact, while others favor a reasoned ex ante evaluation as their standard of evaluation. Still others might give priority to how they felt when experiencing the course of life.

Imagine people who see happiness or high individual welfare as something like the "positive, persistent attitude towards both particular experiences and life experience more generally that a person feels upon repeated reflection" (Kelman 2005: 408). For them, general evaluations of their satisfaction with life as a whole might be an appropriate metric to capture judgments about individual welfare. For people equating individual welfare with moment-to-moment affect, individual welfare might be best measured by approaches such as the experience sampling method or the DRM.

\section{c) Reviews of the new approach}

In addition to specific reviews on the measurement of subjective well-being from an economic perspective and on the potential of the approach to capture individual welfare, there 
are several reviews assessing the new approach in general. Most prominence gained the early survey by Frey and Stutzer (2002b). The authors published it in the Journal of Economic Literature therewith making many economists aware of the new and exciting field of research. Other valuable review articles include, for example, Di Tella and MacCulloch (2006), Dolan et al. (2008) and Stutzer and Frey (2010). Reviews in books are provided in Bruni and Porta (2005, 2007), Diener et al. (2010), Frey and Stutzer (2002a), Frey (2008), Layard (2005) and van Praag and Ferrer-i-Carbonell (2004).

\section{Determinants of Subjective Well-Being}

A large part of happiness research in economics explores the determinants of subjective wellbeing. It is motivated by the ambition to understand the drivers of individual well-being in order to improve the human lot. In essence, causal relationships and pathways have to be identified to pursue this route. Thus, all the identification issues emerge that are well known in economic evaluation research. While experiments are attractive to approach identification issues, they are still rare with respect to the conditions of well-being. ${ }^{2}$ Accordingly, researchers have to be creative in deriving insights from less than optimal data. In this respect, the study of individual panel data derived from repeated representative surveys of the same persons turned out to be productive. It allows for the control of unobserved individual-specific characteristics that might well be correlated with individual reporting behavior, as well as with the experience of some condition such as unemployment, for example. Similarly, the study of repeated cross-sections at the country level allows for control over factors that generate unobserved heterogeneity between countries. As countries differ in many respects, even with the inclusion of numerous control variables, partial correlations from simple crosssection analyses are at risk of an omitted variable bias. Moreover, as almost any factor can be imagined to have a direct influence on a person's well-being, instrumental variable approaches are difficult to convincingly apply.

Despite these inherent difficulties in the study of the determinants of happiness, many valuable insights have been provided. Moreover, economists have started to explore the effect of positive and negative affect as well as life satisfaction on behavior. ${ }^{3}$ The better the mutual relationship is understood, the firmer conclusions about the sources of individual well-being are possible.

\section{a) Income}

Within the many factors that potentially affect human well-being, income is by far the most prominent in economic happiness research. This might not come as a surprise as income or a person's material living standard, normally captured by GDP or GNP, is the main empirical indicator of individual welfare in received economics. To put into doubt that income and happiness are close correlates, constitutes an important challenge to traditional economics.

\footnotetext{
${ }^{2}$ For an application in development economics, see Cattaneo et al. (2009).

${ }^{3}$ In a controlled experiment, for example, the effect of positive affect on time preference is studied revealing a lower present orientation (Ifcher and Zarghamee 2011).
} 
Many empirical tests reveal a substantial correlation of higher income with higher subjective well-being. This holds for people living in households with a high income and/or earning a high labor income but also in general for people living in a rich rather than in a poor country. The controversy emerges, when it comes to the relationship between income growth and the development of subjective well-being over time. Are the empirical observations consistent with the cross-section correlation between income per capita and average subjective wellbeing across countries? Does income growth produce higher average subjective well-being? Proponents of the Easterlin Paradox claim that it does not (e.g., Easterlin et al. 2010). In contrast, critics of the relativist position see the findings compatible with absolute income contributing to higher subjective well-being (e.g., Stevenson and Wolfers 2008). Clark et al. (2008) review this debate as well as the potential explanations.

The issue is still open largely because of limited long-term data for a large sample of countries. Statistical tests are not powerful enough to reject the hypotheses that there is no correlation between income growth and happiness growth as well as that the correlation between income growth and happiness growth is statistically significantly smaller than the one implied by the cross-section correlation between income per capita and average subjective well-being in a country. Sample selection is important in such tests. Is evidence for the US - where there seems to be no long-term correlation between income growth and happiness - sufficient to support the claim? Do we interpret the income development in the transition economies as long-term growth or as a recovery from the historic break-up of communism and the command economy?

The latter question hints at an even bigger challenge in the interpretation of the happiness development in countries over time. What are the underlying processes and causal relationships that lead to the observed correlations between income and happiness? To what extent does a happy population indicate conditions that are conducive to a prosperous economy? There might well be factors like favorable political institutions that promote happiness as well as economic success. Happiness in nations might then well capture the extent to which the institutional structure in a society allows people to benefit from the organizational and technological possibility frontier.

There are also more traditional arguments questioning GDP as an indicator of people's welfare. For example, not all the sources for increases in statistically measured national income are considered welfare enhancing. Public expenditures for reconstruction after a catastrophe are a prominent one.

For us, the lesson to accept is that there is more than absolute income. The level of income captures more than a relative position either within a society or between societies. This aspect has been fruitfully explored in the economics of happiness (see Clark et al. 2008 for a review). In particular, the notion of relative income has been filled with empirical content. The impact of the relative income position within one's neighborhood is convincingly explored in Luttmer (2005) showing a negative effect of local average earnings on selfreported happiness ceteris paribus, i.e. controlling for an individual's own income. This empirical finding is consistent with the idea that people form aspirations about their income based on social comparisons and due to processes of adaptation to previous income. Income 
aspirations have been empirically approximated based on people's reports about what they consider a sufficient income for their household. Reported subjective well-being is found to strongly depend on the discrepancy between household income and the reported aspirations (e.g., Stutzer 2004, Knight and Gunatilaka 2012). Income aspirations thus seem an important mediator variable when we want to understand how income and subjective well-being are related.

Many questions have remained open so far. What are the drivers of income aspirations and when they are formed by social comparisons - who compares to whom? Interesting first insights are provided based on recent survey evidence (Clark and Senik 2010). For example, high-income people engage less in income comparisons than low-income people and colleagues are the most prominent reference group. Another issue concerns the marginal utility of income. Previous research provides evidence that the elasticity with respect to income is smaller than minus one (Layard et al. 2008). However, partial correlations for the effect of income on subjective well-being are often difficult to interpret. This not only holds in cross-section analyses involving issues of reversed causality and omitted variable bias but also in panel data studies. Our concern refers to the limited available information about the reasons for the variation in people's or households' income. If people earn more because they put in more effort or time or accept a more stressful job, these income gains are fundamentally different from some vague idea of a windfall income gain. In recent work, new sources for income variation have been exploited to get a better idea of the marginal utility of income, like, for example, inter-industry wage differentials (Pischke 2011).

\section{b) Employment}

There is a long tradition of research on the conditions at the workplace that contribute to a satisfying job: People are either directly asked about the importance of various job attributes, or the determinants of reported job satisfaction are explored in multiple regression analyses. This research is meaningfully complemented by recent work on general well-being or life satisfaction in economics. A productive comparison is the one between employees and selfemployed people revealing that autonomy on the job is a valuable source of utility for which self-employed people are willing to accept a lower expected salary (Frey and Benz 2008). Probably even more is revealed about employment as a source of individual well-being if the phenomenon of unemployment is taken into account.

In early contributions reprinted in Easterlin (2002), as well as in many more recent empirical analyses, being unemployed is related to systematically lower subjective well-being than being employed. This holds even if the loss in income is statistically taken into account. It reflects that individual unemployment involves psychic costs due to a loss of social status, self-esteem, personal relationships and a disciplining time structure bound to a workplace.

In recent work, this general insight has been refined. For example, company closures are studied as a reason of unemployment revealing large non-pecuniary costs of job loss (Kassenboehmer and Haisken-DeNew 2009). In other work, the psychic costs of unemployment are related to social work norms (Clark 2003, Stutzer and Lalive 2004). Moreover, long-term studies reveal limited adaptation to unemployment (Clark 2006) as well 
as negative effects on subjective well-being even after re-employment, so called scarring effects (Clark et al. 2001, Knabe and Rätzel 2011). However, it is also observed that momentto-moment net affect need not be lower for unemployed people even if they report significantly lower satisfaction with their life (Knabe et al. 2010).

High unemployment rates also have negative effects on people who are not personally affected by unemployment. Based on Eurobarometer data from 12 European countries between 1975 and 1992, Di Tella et al. (2003) show that aggregate unemployment decreases average reported life satisfaction beyond changes in aggregate income. The potential reasons include direct effects of unemployment on crime and public finances, but also aspects specific to the workplace like changes in working hours and salaries. Moreover, high unemployment also affects anticipated economic distress. For instance, the probability that a worker may himself experience a spell of unemployment in the future increases. A related literature documents the importance of self-reported job security for individuals' well-being (see, e.g., Green 2011).

In an empirical study, Luechinger et al. (2010) isolate the latter source of reduced individual welfare: the negative anticipatory feelings of angst and stress due to economic insecurity. In order to distinguish between general negative externalities of unemployment and changes in economic risks to individuals, workers are studied in two sectors of the economy that differ fundamentally in their exposure to economic shocks - people working in the private sector and those working in the public sector. Public sector employees usually enjoy extended protection from dismissal and work in organizations that very rarely go bankrupt. In their study for Germany, they find that people working in the private sector are affected more strongly by general economic shocks than are those working in the public sector. This suggests that a substantial fraction of the psychic costs brought about by general unemployment is due to increased economic insecurity.

\section{c) Social capital}

In order to put the economic determinants of happiness into perspective, the study of alternative sources of well-being is revealing. It turns out that happiness depends much on personal relationships, i.e. the quantity and quality of social relations that people have with family, friends, work mates and fellow community members. If these relationships, often referred to as social capital, are good, people experience high subjective well-being (for a review, see Helliwell and Putnam 2004, Powdthavee 2008).

Importantly, the benefits of social capital are not confined to outcomes like informal mutual assistance or the access to valuable information due to weak ties. There is rather a strong non instrumental component of interpersonal relationships that contributes to individual wellbeing. These so called relational goods involve socializing as an important aspect. They also have a public good component as one persons' engagement in social relations makes them more rewarding for others (Becchetti et al. 2008). In addition to socializing, there is also empirical evidence that performing volunteer work is rewarding in itself (e.g., Meier and Stutzer 2008). 
Given the importance of social relations for human well-being, changes in their quality have been argued to drive long-term trends in people's reported subjective well-being (Bartolini 2012, Sarracino 2010). To what extent the development of happiness over time has to be understood as an interaction between economic factors and aspects of social capital is so far an open issue.

\section{d) Health}

Researchers in social sciences other than economics have been studying the relationship between health and happiness for years. They document negative correlations between ill health and subjective well-being. Economists are reluctant to claim the identification of causal effects going from health to happiness. Happy people might well forget about physical health problems or disregard them when asked. In fact, there is convincing evidence for happiness being beneficial for health and for increasing longevity (Diener and Chan 2011). In addition to reverse causality, there is the issue of third variables affecting both happiness and health. Important candidates are a person's personality or genetic make-up that affect in particular mental health.

Despite the inherent difficulties in exploring the relationship between health and happiness, there are interesting insights from economics in this area. For example, people who become disabled are found to experience lower life satisfaction particularly so in case of severe disability. Moreover, there is evidence for adaptation. Importantly though, people only partly adapt to their situation. Within the first three years, fifty percent of the effect for moderate and thirty percent for severe disability dissipates (Oswald and Powdthavee 2008). There is also evidence that the marginal utility of consumption varies with health. Based on measures of subjective well-being, Finkelstein et al. (2013) find that a deterioration in health is associated with a decline in the marginal utility of consumption.

At the aggregate level, health measured in terms of life expectancy is found to play a limited role in explaining cross-country patterns in subjective well-being (Deaton 2008 [12]). Controlling for per capita income, life expectancy is not correlated with average life satisfaction, neither is a variable that identifies countries with high HIV prevalence. In contrast, changes in life expectancy are found to be positively correlated with life satisfaction. Given that health and life expectancy are often considered welfare indicators much further research seems advisable.

\section{e) Additional factors}

There are, of course, many more factors that affect individuals' well-being and that are of interest to economists. This not only holds for economic variables like inflation (see, e.g., Wolfers 2003) or income inequality (see, e.g., Alesina et al. 2004) but also for sociodemographic characteristics that are affected by public policy such as, for example, the level of education (see, e.g., Oreopoulos and Salvanes 2011). Moreover, political economists emphasize the role of basic political institutions of democracy and federalism (e.g., Frey and Stutzer 2000), while environmental economists hint to evidence on, for example, the effect of 
air pollution on people's subjective well-being (see next section). Additional references to many of these factors can be found in the survey papers mentioned above.

\section{Valuing Public Goods: The Life Satisfaction Approach}

The study of happiness data provides evidence on the extent to which living conditions are adverse or favorable to people. For example, environmental degradation may be reflected in lower subjective well-being. This line of empirical research opens up a new approach for the valuation of public goods. The benefits derived from public goods are inherently difficult to measure because they are not directly exchanged on markets. But public agencies in particular have a demand for the measurement of preferences for public goods. Increasingly, they are required by law to provide cost-benefit analyses to evaluate the social desirability of government programs.

The economics of happiness provides a promising complementary method that avoids some of the major difficulties inherent in previous approaches to value public goods. ${ }^{4}$ It is called the "Life Satisfaction Approach" (LSA) (for a review, see, Frey et al. 2010). As this review of the LSA explains, public goods can be directly evaluated in utility terms when reported subjective well-being is used as a proxy measure for individual welfare. The marginal utility of public goods or the disutility of public bads is estimated by correlating the amount of public goods or public bads with individuals' reported subjective well-being. By measuring these marginal utilities as well as the marginal utility of income, the trade-off ratio between income and the public good can be calculated. ${ }^{5}$

Van Praag and Baarsma (2005) pioneered and successfully applied this approach. They use it to value airport nuisance in Amsterdam. The LSA has been further developed by Luechinger (2009) who applies an advanced identification strategy in order to value the negative consequences of sulfur dioxide in Germany.

The LSA has also been used to value other forms of air pollution (Welsch 2006, MacKerron and Mourato 2009), terrorism (Frey et al. 2009), droughts (Carroll et al. 2009), flood hazards (Luechinger and Raschky 2009), and scenic amenities (Ambrey and Fleming 2011). Recent studies applying the LSA have already reached a high standard, and preconditions for its application are better understood and formulated. What so far was an academically driven development of a new method may soon become an empirical tool to be used in the political process.

\footnotetext{
${ }^{4}$ For different established stated preference and revealed preference methods for the valuation of public goods see, e.g., Freeman (2003).

${ }^{5}$ The LSA is compared to the standard non-market valuation techniques in Kahneman and Sugden (2005) and Dolan and Metcalfe (2008).
} 


\section{Utility Misprediction and Adaptation}

\section{a) Decision versus experienced utility and the potential for suboptimal choices}

In traditional economics, people are assumed to make choices in an optimal manner. An entirely different perspective prevails in popular discourse and most other disciplines. There, it is common to presume that people attempt to maximize their happiness but may not always be effective in doing so. The notion of (non random) mistaken choices, alien to standard economics, is part and parcel of both daily life and most social sciences.

The economics of happiness offers a new angle to explore (potentially) suboptimal choices. In addition to observed behavior reflecting decision utility, there is information about people's experienced utility when they report emotions or some evaluative judgment. In crossdisciplinary research in economics and psychology, various aspects of discrepancies between these two utility and welfare concepts have been explored. Some key insights and conceptual considerations are nicely presented in Kahneman and Thaler (2006). ${ }^{6}$

Of particular interest is people's misprediction of experienced utility expected in the future when they make decisions in the present (also called projection bias in the theoretical work of Loewenstein et al. 2003). People often hold incorrect intuitive theories about the determinants of happiness. For instance, they overestimate the impact of specific life events on their experienced well-being with regard to intensity, as well as with regard to duration. In fact, people seem to systematically underestimate adaptation to changes in circumstances or repeated stimuli. Rayo and Becker (2007) model this aspect of evaluating alternatives based on a happiness function that is evolutionary efficient. In their model, there is a time-varying reference point in the happiness function that provides optimal incentives for fitness. ${ }^{7}$ To what extent this tendency of human nature is still productive in the modern world, is a different question.

Adaptation is a fundamental process in the formation of happiness and thus inspires our understanding of utility in economics. Research on the economics of happiness has documented patterns of adaptation in many areas of life whereby the degree of adaptation seems to systematically differ across experiences (Clark et al. 2008, Frijters et al. 2011).

\section{b) Economic consequences of mispredicting utility}

If the underestimation of adaptation is taken into account together with differences in adaptation across activities and domains, interesting implications emerge. First, many economic decisions are best understood as trade-offs that involve the allocation of money,

\footnotetext{
${ }^{6}$ In Hsee et al. (2012), evidence on suboptimal choices is reviewed that arise for two reasons. First, people mispredict the utility they may experience form the available choice options due to the evaluation mode. Second, people make choices based on salient rules that are unlikely to maximize happiness.

${ }^{7}$ A related evolutionary model for processes of adaptation and resilience builds on the idea of a hedonic capital and differentiates between stocks and flows of psychological resources (Graham and Oswald 2010).
} 
effort and time. Then, for at least two alternatives, predictions about experienced utility are necessary. In this constellation, the predictions can systematically differ in their adequacy. If people choose options according to a biased evaluation, their experienced utility will be lower than what they could otherwise enjoy. Moreover, they consume different goods with different attributes and pursue different activities than in a situation where either no option in the choice set poses a prediction problem or the degree of prediction bias is similar across alternatives.

Asymmetric prediction biases are most likely if trade-offs across life domains are to be undertaken. People often overestimate experienced utility from material consumption, because they underestimate the power of hedonic adaptation to material living standards. In contrast, positive experiences from social, challenging and autonomous activities are less susceptible to hedonic adaptation as they are constantly renewed. Accordingly, in trade-offs, too much weight is given to material goods relative to goods and activities that involve social engagement, or provide for the experience of competence and autonomy (Frey and Stutzer 2012).

This result is consistent with the general claim that people overvalue income relative to leisure and that the "work-life balance" of individuals today is distorted. People are induced to work too much and to disregard other aspects of life. This proposition is frequently put forward for career people who are said to be "overworked". A related issue is status from conspicuous consumption. Competing for status involves negative externalities and therefore too much effort (from an aggregate perspective) is invested in gaining status and acquiring "positional goods" (Frank 2004). If there is a comparatively large prediction bias in experience from consumption, the distortions induced by competing for status in consumption are magnified.

Utility misprediction also helps to better understand individual choices involving a trade-off with commuting. Commuters compare the salary or the quality of housing on the one hand and commuting time on the other hand. Rational utility maximizers only commute when they are compensated for the cost of traveling. However, when people overestimate utility from goods, they are expected to opt for too much commuting and suffer lower experienced utility. In an empirical test using data on reported subjective well-being, people's decision to commute for longer or shorter hours was analyzed (Stutzer and Frey 2008). It is found that commuting is far from being fully compensated. Moreover, people do not adapt to commuting while they get used to the higher labor income. If this asymmetry is neglected in trade-offs, suboptimal choices result.

\section{Implications for Public Policy}

The study of individual happiness has enriched economics with many new and sometimes challenging (preliminary) insights. More and more often, it is asked about the policy consequences that are to be derived from these insights. This discourse was successfully stimulated by the Stiglitz-Sen-Fitoussi Commission on the "Measurement of Economic Performance and Social Progress" (Stiglitz et al. 2009). Recently, a World Happiness Report (Helliwell et al. 2012) has been published developing the aspects on subjective well-being 
further. Alongside, many think tanks have taken up the issue of happiness and public policy (see, e.g., Booth 2012).

At least two general perspectives prevail when it comes to happiness policy. Many understand happiness policy as does Layard (2006) who wants to incorporate the insights of the economics of happiness directly into public policy. The cost-benefit framework of traditional welfare economics is to be retained. This perspective has attractive features: First, it enables one to derive optimal policies in a numerical way. Second, in contrast to postulating a purely theoretical social welfare function at the aggregate level based on a wide range of different outcome variables, the well-being figures provided by happiness research offer an overall empirical evaluation based on individuals' judgments. Third, a measure of social welfare based on happiness data is democratic in the sense of attributing equal weight to every person.

In contrast, Frey and Stutzer (2012) propose to use the insights of public choice theory to develop the foundations of happiness policy. They emphasize that for politico-economic reasons an optimal happiness policy maximizing some aggregate happiness indicator corresponds to a benevolent dictator approach. They propose instead a constitutional perspective focusing on a comparative institutional analysis of subjective well-being. Their vision rests on the fundamental presumption that the quality of the political process is key to people's happiness. The legitimacy of political action finally rests on the voluntary agreements of the citizens involved. The sovereignty of individuals should not be reduced to their self-reports of well-being. Accordingly, the results gained from happiness research should be taken as inputs into the democratic political process. These inputs still have to prove themselves in political competition and in the discourse among citizens, as well as between citizens and politicians.

With this perspective in mind, there are many open issues for positive analyses in the economic of happiness. We are convinced that soon further advances can be reviewed. 


\section{References}

Alesina, Alberto, Rafael Di Tella and Robert MacCulloch (2004). Inequality and Happiness: Are Europeans and Americans Different? Journal of Public Economics 88: 2009-2042.

Ambrey, Christopher L. and Christopher M. Fleming (2011). Valuing Scenic Amenity Using Life Satisfaction Data. Ecological Economics 72: 106-115.

Bartolini, Stefano (2012). Sociability Predicts Happiness in Nations: Evidence from Macro and Micro Data. Forthcoming in Stefano Bartolini (ed.). Policies for Happiness. Oxford: Oxford University Press.

Baetschmann, Gregori, Kevin E. Staub and Rainer Winkelmann (2011). Consistent Estimation of the Fixed Effects Ordered Logit Model. IZA Discussion Paper No. 5443. Bonn: IZA.

Becchetti Leonardo, Alessandra Pelloni and Fiammetta Rossetti (2008). Relational Goods, Sociability, and Happiness. Kyklos 61(3): 343-363.

Booth, Philip (ed.) (2012). ... and the Pursuit of Happiness. Wellbeing and the Role of Government. London: Institute of Economic Affairs.

Bruni, Luigino and Pier Luigi Porta (eds.) (2005). Economics and Happiness. Framing the Analysis. Oxford: Oxford University Press.

Bruni, Luigino and Pier Luigi Porta (eds.) (2007). Handbook on the Economics of Happiness. Cheltenham, UK: Edward Elgar.

Carroll, Nick, Paul Frijters and Michael A. Shields (2009). Quantifying the Costs of Drought: New Evidence from Life Satisfaction Data. Journal of Population Economics 22(2): 445-461.

Cattaneo, Matias D., Sebastian Galiani, Paul J. Gertler, Sebastian Martinez and Rocio Titiunik (2009). Housing, Health, and Happiness. American Economic Journal: Economic Policy 1(1): 75-105.

Clark, Andrew E. (2003). Unemployment as a Social Norm: Psychological Evidence from Panel Data. Journal of Labor Economics 21(2): 323-351.

Clark, Andrew E. (2006). A Note on Unhappiness and Unemployment Duration. Applied Economics Quarterly 52(4): 291-308

Clark, Andrew, Yannis Georgellis and Peter Sanfey (2001). Scarring: The Psychological Impact of Past Unemployment. Economica 68(270): 221-241.

Clark Andrew, Ed Diener, Yannis Georgellis and Richard E. Lucas (2008). Lags and Leads in Life Satisfaction: A Test of the Baseline Hypothesis. Economic Journal 118(529): F222-F243.

Clark Andrew, Paul Frijters and Mike Shields (2008). Relative Income, Happiness and Utility: An Explanation for the Easterlin Paradox and Other Puzzles. Journal of Economic Literature 46(1): 95-144.

Clark, Andrew and Claudia Senik (2010). Who Compares to Whom? The Anatomy of Income Comparisons in Europe. Economic Journal 120(544): 573-594.

Deaton Angus (2008). Income, Health, and Well-being Around the World: Evidence from the Gallup World Poll. Journal of Economic Perspectives 22(2): 53-72.

Di Tella, Rafael and Robert MacCulloch (2006). Some Uses of Happiness Data in Economics. Journal of Economic Perspectives 20(1): 25-46.

Di Tella Rafael, Robert J. MacCulloch and Andrew J. Oswald (2003). The Marcoeconomics of Happiness. Review of Economic and Statistics 85(4): 809-827.

Diener, Ed, John F. Helliwell and Daniel Kahneman (2010). International Differences in Well-Being. New York: Oxford University Press. 
Diener, Ed and Micaela Y. Chan (2011). Happy People Live Longer: Subjective Well-Being Contributes to Health and Longevity. Applied Psychology: Health and Well-Being 3(1): $1-43$.

Dolan, Paul and Robert Metcalfe (2008). Comparing Willingness-to-Pay and Subjective WellBeing in the Context of Non-Market Goods. Centre for Economic Performance Discussion Paper No. 0890, London: LSE.

Dolan, Paul, Tessa Peasgood and Mathew White (2008). Do We Really Know What Makes Us Happy? A Review of the Economic Literature on the Factors Associated with Subjective Well-Being. Journal of Economic Psychology 29(1): 94-122

Easterlin, Richard A. (ed.) (2002). Happiness in Economics. Cheltenham: Edward Elgar.

Easterlin Richard A., Laura Angelescu McVey, Malgorzata Switek, Onnicha Sawangfa and Jacqueline Smith Zweig (2010). The Happiness-Income Paradox Revisited. Proceedings of the National Academy of Sciences 107(52): 22463-22468.

Ferrer-i-Carbonell, Ada and Paul Frijters (2004). How Important is Methodology for the Estimates of the Determinants of Happiness? Economic Journal 114(497): 641-659.

Finkelstein, Amy, Erzo F.P. Luttmer and Matthew J. Notowidigdo (2010). What Good Is Wealth Without Health? The Effect of Health on the Marginal Utility of Consumption. Mimeo, Dartmouth College.

Frank, Robert H. (2004). How not to Buy Happiness. Daedalus 133(2): 69-79.

Freeman, A. Myrick, III. (2003). The Measurement of Environmental and Resource Values: Theory and Methods. Washington, DC.: Resources for the Future.

Frey, Bruno S. (2008). Happiness: A Revolution in Economics. Cambridge, MA: MIT Press.

Frey, Bruno S. and Matthias Benz (2008). Being Independent is a Great Thing: Subjective Evaluations of Self-Employment and Hierarchy. Economica 75(298): 362-383.

Frey, Bruno S. and Alois Stutzer (2002a). Happiness and Economics: How the Economy and Institutions Affect Well-Being. Princeton and Oxford: Princeton University Press.

Frey Bruno S. and Alois Stutzer (2002b). What Can Economists Learn from Happiness Research? Journal of Economic Literature 40(2): 402-435.

Frey Bruno S. and Alois Stutzer (2012). The Use of Happiness Research for Public Policy. Social Choice and Welfare 38(4): 659-674.

Frey, Bruno S. and Alois Stutzer (2012). Economic Consequences of Mispredicting Utility. Mimeo, University of Basel.

Frey, Bruno S., Simon Luechinger and Alois Stutzer (2009). The Life Satisfaction Approach to the Value of Public Goods: The Case of Terrorism. Public Choice 138(3-4): 317-345.

Frey, Bruno S., Simon Luechinger and Alois Stutzer (2010). The Life Satisfaction Approach to Environmental Valuation. Annual Review of Resource Economics 2: 139-160.

Frijters, Paul, David W. Johnston and Michael A. Shields (2011). Life Satisfaction Dynamics with Quarterly Life Event Data. Scandinavian Journal of Economics 113(1): 190-211.

Graham, Liam and Andrew Oswald (2010). Hedonic Capital, Adaptation and Resilience. Journal of Economic Behavior and Organization 76(2): 372-384.

Green, Francis (2011). Unpacking the Misery Multiplier: How Employability Modifies the Impacts of Unemployment and Job Insecurity on Life Satisfaction and Mental Health. Journal of Health Economics 30(2): 265-276.

Helliwell, John and Christopher Barrington-Leigh (2010). Measuring and Understanding Subjective Well-Being. Canadian Journal of Economics 43(3): 729-753.

Helliwell John and Robert D. Putnam (2004). The Social Context of Well-Being. Philosophical Transactions of the Royal Society of London, Series B. Biological Sciences 359(1449): 1435-1446.

Helliwell, John F., Richard Layard and Jeffrey Sachs (eds.) (2012). World Happiness Report. New York: The Earth Institute, Columbia University. 
Hsee, Christopher, Yuval Rottenstreich and Alois Stutzer (2012). Suboptimal Choices and the Need for Experienced Individual Well-Being in Economic Analysis. IZA Discussion Paper No. 6346, Bonn: IZA.

Ifcher, John and Homa Zarghamee (2011). Happiness and Time Preference: The Effect of Positive Affect in a Random-Assignment Experiment. American Economic Review 101(7): 3109-3129.

Kahneman, Daniel and Robert Sugden (2005). Experienced Utility as a Standard of Policy Evaluation. Environmental and Resource Economics 32(1): 161-81.

Kahneman Daniel and Alan B. Krueger (2006). Developments in the Measurement of Subjective Well-Being. Journal of Economic Perspectives 20 (1): 3-24.

Kahneman Daniel and Richard H. Thaler (2006). Anomalies: Utility Maximization and Experienced Utility. Journal of Economic Perspectives 20(1): 221-234.

Kahneman, Daniel, Alan Krueger, David Schkade, Norbert Schwarz and Arthur Stone (2004). A Survey Method for Characterizing Daily Life Experience: The Day Reconstruction Method. Science 306(5702): 1776-1780.

Kassenboehmer, Sonja C. and John P. Haisken-DeNew (2009). You're Fired! The Causal Negative Effect of Entry Unemployment on Life Satisfaction. Economic Journal 119(536): 448-462.

Kelman Mark (2005). Hedonic Psychology and the Ambiguities of "Welfare". Philosophy and Public Affairs 33(4): 391-412.

Knabe, Andreas and Steffen Rätzel (2011). Scarring or Scaring? The Psychological Impact of Past Unemployment and Future Unemployment Risk. Economica 78(310): 283-293.

Knabe, Andreas, Steffen Rätzel, Ronnie Schöb and Joachim Weimann (2010). Dissatisfied with Life but Having a Good Day: Time-Use and Well-Being of the Unemployed. Economic Journal 120(547): 867-889.

Knight, John and Ramani Gunatilaka (2012). Income, Aspiration and the Hedonic Treadmill in a Poor Society. Journal of Economic Behavior and Organization 82(1): 67-81.

Krueger, Alan B. and David A. Schkade (2008). The Reliability of Subjective Well-Being Measures. Journal of Public Economics 92(8-9): 1833-1845.

Krueger, Alan B. (ed.) (2009). Measuring the Subjective Well-Being of Nations: National Accounts of Time Use and Well-Being. Chicago: University of Chicago Press.

Layard, Richard (2005). Happiness: Lessons from a New Science. New York: Penguin.

Layard Richard (2006). Happiness and Public Policy: A Challenge to the Profession. Economic Journal 116(510): C24-C33.

Layard, Richard, Stephen Nickell and Guy Mayraz (2008). The Marginal Utility of Income. Journal of Public Economics 92(8-9): 1846-1857.

Loewenstein, George, Ted O'Donoghue and Matthew Rabin (2003). Projection Bias in Predicting Future Utility. Quarterly Journal of Economics 118(4): 1209-1248.

Luechinger Simon (2009). Valuing Air Quality Using the Life Satisfaction Approach. Economic Journal 119(536): 482-515.

Luechinger, Simon and Paul A. Raschky (2009). Valuing Flood Disasters Using the Life Satisfaction Approach. Journal of Public Economics 93(3-4): 620-633.

Luechinger, Simon, Stephan Meier and Alois Stutzer (2010). Why Does Unemployment Hurt the Employed? Evidence from the Life Satisfaction Gap between the Public and the Private Sector. Journal of Human Resources 45(4): 998-1045.

Luttmer Erzo (2005). Neighbours as Negatives: Relative Earnings and Well-Being. Quarterly Journal of Economics 120(3): 963-1002.

MacKerron, George and Susana Mourato (2009). Life satisfaction and Air Quality in London. Ecological Economics 68(5): 1441-1453. 
Meier, Stephan and Alois Stutzer (2008). Is Volunteering Rewarding in Itself? Economica 75(297): 39-59.

Oreopoulos, Philip and Kjell Salvanes (2011). Priceless: The Nonpecuniary Benefits of Schooling. Journal of Economic Perspectives 25(1): 159-184.

Oswald, Andrew and Nattavudh Powdthavee (2008). Does Happiness Adapt? A Longitudinal Study of Disability with Implications for Economists and Judges. Journal of Public Economics 92(5-6): 1061-1077.

Oswald, Andrew and Steve Wu (2010). Objective Confirmation of Subjective Measures of Human Well-being: Evidence from the USA. Science 327 (5965): 576-579.

Pischke, Jorn-Steffen (2011). Money and Happiness: Evidence from the Industry Wage Structure. NBER Working Papers No. 17056, Cambridge: National Bureau of Economic Research.

Powdthavee, Nattavudh (2008). Putting a Price Tag on Friends, Relatives, and Neighbours: Using Surveys of Life Satisfaction to Value Social Relationships. Journal of SocioEconomics 37(4): 1459-1480.

Rayo Luis and Gary S. Becker (2007). Evolutionary Efficiency and Happiness. Journal of Political Economy 115(2): 302-337.

Sarracino, Francesco (2010). Social Capital and Subjective Well-Being Trends: Comparing 11 Western European Countries. Journal of Socio- Economics 39(4): 482-517.

Stevenson Betsey and Justin Wolfers (2008). Economic Growth and Subjective Well-Being: Reassessing the Easterlin Paradox. Brookings Papers on Economic Activity 39(1): 1102.

Stiglitz, Joseph E. et al. (2009). Report by the Commission on the Measurement of Economic Performance and Social Progress. Accessible under www.stiglitz-sen-fitoussi.fr.

Stone Arthur, Saul Shiffman and Marten DeVries (1999). Ecological Momentary Assessment. In: Daniel Kahneman, Ed Diener and Norbert Schwarz (eds.). Well-Being: The Foundations of Hedonic Psychology. New York, NY: Russell Sage Foundation: 26-39.

Stutzer Alois (2004). The Role of Income Aspirations in Individual Happiness. Journal of Economic Behaviour and Organization 54(1): 89-109.

Stutzer, Alois and Bruno S. Frey (2008). Stress That Doesn't Pay: The Commuting Paradox. Scandinavian Journal of Economics 110(2): 339-366.

Stutzer, Alois and Bruno S. Frey (2010). Recent Advances in the Economics of Individual Subjective Well-Being. Social Research: An International Quarterly 77(2): 679 - 714.

Stutzer, Alois and Rafael Lalive (2004). The Role of Social Work Norms in Job Searching and Subjective Well-Being. Journal of the European Economic Association 2(4): 696719.

van Praag Bernard M.S. and Barbara E. Baarsma (2005).Using Happiness Surveys to Value Intangibles: The Case of Airport Noise. Economic Journal 115(500): 224-246.

van Praag, Bernard M.S. and Ada Ferrer-i-Carbonell (2004). Happiness Quantified - A Satisfaction Calculus Approach. Oxford: Oxford University Press.

Welsch, Heinz (2006). Environment and Happiness: Valuation of Air Pollution Using Life Satisfaction Data. Ecological Economics 58(4): 801-813.

Wolfers, Justin (2003). Is Business Cycle Volatility Costly? Evidence from Surveys of Subjective Well-Being. International Finance 6(1): 1-26. 